\title{
Medical students call for more education on climate change
}

\author{
n Cite as: CMAJ 2019 March 11;191:E291-2. doi: 10.1503/cmaj.109-5717
}

Posted on cmajnews.com on Feb. 19, 2019.

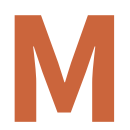
edical students across Canada are pushing for a greater emphasis on climate change in medical education. A group within the Canadian Federation of Medical Students (CFMS) is drafting a set of recommended curricular competencies with a goal of seeing them implemented in 2020.

Health problems caused by air pollution, food and water insecurity, and natural disasters are among the issues that the Health and Environment Adaptive Response Task Force (HEART) hopes to see taught.
"There are many ways that the change in the environment is going to impact our patients," said Finola Hackett, chair of HEART. "The better we understand them now, the better we can adapt."

HEART's efforts are part of a larger movement. In November, the Lancet Countdown recommended that climate change be integrated into all medical and health science curricula. The authors pointed to a heat wave in Quebec last summer that is suspected to have contributed to more than 90 deaths as an

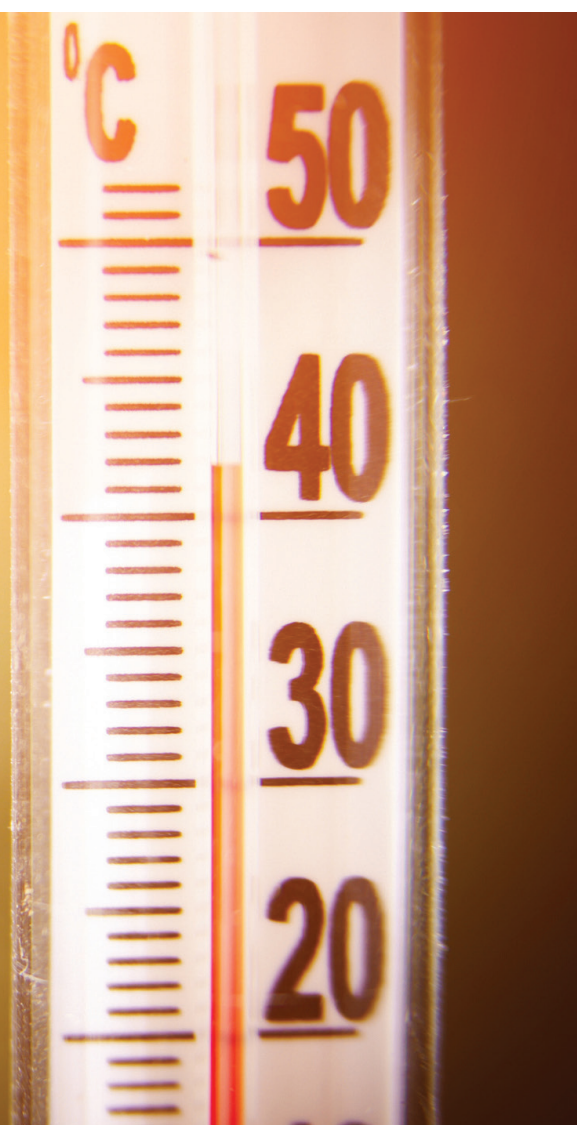

Deaths associated with a heat wave in Quebec last summer have been cited as an example of how global warming affects health. example of the health effects of global warming. The International Federation of Medical Students' Associations (IFMSA) is also advocating for the inclusion of climate change in medical curricula worldwide by 2020.

HEART plans to ask students across the country to assess the current state of climate change education in their faculties to establish a baseline and measure uptake in years to come. Data collection is set to begin soon, with plans to present a report in April.

Canadian medical students have already begun documenting their international peers' perceptions of climate change in medical education. A group led by George Kitching and Adrina Zhong at Western University's Schulich School of Medicine and Dentistry interviewed 18 students from 16 countries at a recent IFMSA meeting in Quebec. Their initial results suggest students are concerned about the health impacts of climate change and feel that current teaching is inadequate.

Kitching, who is leading HEART's data collection effort, thinks climate change education is important because future physicians will be dealing with its health impacts. For Zhong, educating medical practitioners about climate change and, by proxy, their patients, makes the issue more relatable and may motivate the public to pay more attention to the problem.

But according to Caroline Wellbery, a professor at Georgetown University who studies climate change and health in medical education, making curriculum changes can be challenging. Wellbery recently published an article arguing that the topic should be more widely taught, but said she understands that curricula 
are crowded and it can be difficult to convince students and faculty that climate change relates directly to their patients.

HEART has received similar feedback, said Hackett. She tries to highlight the ways that climate change will affect patients across specialties in order to encourage students and educators to see it as more than a niche issue.

Ideally, there would be dedicated lectures on climate change, said Hackett. However, to make space in already jam- packed curricula, faculties could at least consider including references to climate change in existing sessions, she suggested. For example, a few slides about air pollution could be added to a course about respiratory illness, and climate change could be mentioned during a refugee health unit. Intermittent, repeated references to climate change could help drive home the message.

"It's how you learn medicine," Hackett said. "Through repetition."
According to the Association of Faculties of Medicine of Canada (AFMC), Canadian medical programs already include the impacts of climate change on environmental, occupational, and public health. Although the AFMC is not developing climate change curricula, it indicated that curricula need to focus on the needs of society, and that social determinants of health and population health are important factors.

Caroline Mercer, Toronto, Ont. 